\title{
Using Literature and Multiple Technologies in ESL Instruction
}

\author{
Moussa Traore \\ North Shore Community College, Danvers, MA, USA \\ Email: motraore@northshore.edu \\ Lydia Kyei-Blankson \\ Illinois State University, Normal, IL, USA \\ Email: 1kyeibl@ilstu.edu
}

\begin{abstract}
Many instructors are using literary texts along with language structure books in English as a Secondary Language (ESL) classrooms. Since literature is often written to portray a particular cultural or authentic experience, the material presented may not be familiar to ESL students. Also, the students may find such texts structurally complex and impossible to understand. To overcome these challenges, instructors need to implement strategies that will make the literary materials relevant and useful to student learning. The current study describes how multiple technologies were successfully employed in the presentation of Chinua Achebe's 1958 novel, Things Fall Apart. In addition, ESL students' reactions to the integration of technology in instruction were explored. Findings from this study have pedagogical implications for instructors who plan to incorporate literature and technology into their ESL curricula.
\end{abstract}

Index Terms - technology, literature, ESL instruction

\section{INTRODUCTION}

Using technology as a supplementary tool to support learning among students is a teaching strategy that continues to gain popularity today. Instructors are currently using various forms of technology to help improve understanding of their course content. Trends in technology have indeed altered the educational landscape and have caused changes in the way courses are developed and delivered (Hicks, Reid, \& George, 2001). Although Smith \& Ayers (2006) are of the view that technology hinders learning, contrary findings on this topic suggest that when used appropriately, technology helps enhance various aspects of learning (Ehrmann, 2002).

One area in which the effects of technology integration have been realized is in the education of students learning English as a second language (ESL). A report from the National Center for ESL Literacy Education (2002) discussed how some professionals use technology such as audio and video tapes, cameras, overhead projectors and software programs to enrich their instructional activities. Empirical research conducted to examine the influence of this approach showed that the use of technology helped motivate ESL learners to develop strategies for successful learning (Mayer, 1999, Moreno, Boire, \& Vagge, 1999, Jelfs \& Whitelock, 2000, Mansoor, 2002). Although the findings from past studies have demonstrated that technology usage may lead to positive learner experiences in ESL classrooms, it must be pointed out that most of the studies were conducted in situations where simplified materials designed for ESL learners was used. The question still remains as to whether this trend will persist when literature is included in the ESL curriculum.

Many scholars have either argued for or against the use of literature in ESL programs. Arguments forwarded against its use include the fact that the language used in the literature is structurally complex, conceptually difficult to understand, and is unique to a particular culture or authentic situation, therefore does not support the goals of teaching grammar in a language classroom and helping students meet their academic and occupational needs (Kay, 1982). Kay presented the following counter-argument:

Certainly, in so far as literature can foster an overall increase in reading proficiency, it will contribute to these goals. An evaluation of reading proficiency rests on an understanding of what is involved in the reading process ......reading necessitates the ability to interact with a text by decoding the language and comprehending the concepts presented (p. 530).

If this argument is supported then the next move is to determine how instructors can successfully use literature in ESL classrooms, specifically with the integration of technology and explore the extent to which technology use helped the instruction in Literature and improved ESL students' understanding of Literature and English proficiency skills. Given that little research has been conducted in this area (Pellicer-Sanchez \& Schmidt, 2010), such a study is important in order to provide ESL instructors with an evidence-based frame of reference.

\section{A. Purpose of the Study}


The purpose of this study was to describe how technology was used to successfully teach literature in an ESL class and explore the affect on students' vocabulary skills and their reactions to the use of literature and technology in their learning. For the purposes of this study, a novel written by Chinua Achebe (1958) entitled Things Fall Apart was used. Some of the language used in the text is very authentic to the Igbo culture in Nigeria. In addition, this book portrays colonization, an experience and a theme that was very unfamiliar to the ESL students who participated in the study.

\section{B. Research Questions}

The questions that guided this study include:

1. What did the ESL students acquire from the use of literature in their classroom?

2. How did the students perceive the effect of technology integration in the teaching of literature on their learning?

3. In what specific ways did the variety of technology used help student understand the concepts presented in the authentic text?

\section{Significance of the Study}

Several benefits may be derived from this study. First, faculty who teach literature may find it useful to know how technology facilitates the teaching and learning of literature. Second, ESL faculty might realize the benefits of integrating literature instruction with technology and its implications for ESL students' learning. Finally, education administrators may realize through this study the importance of technology integration in the teaching and learning of literature especially to ESL students.

\section{REVIEW OF LITERATURE}

In this review themes related to the current study are presented. First the approaches and methods in language teaching in ESL classrooms are reviewed. Next, the importance of including literature or literary texts in the ESL curriculum is addressed. Finally, issues related to technology integration in ESL instruction are discussed.

\section{A. Approaches and Methods in ESL Teaching}

According to $\mathrm{Li}$ (2006), language acquisition among young children is a gradual process that involves building vocabulary from messages received through communication and using the language in a highly supportive, nonstressful environment. Li goes on to point out that

"it is exactly these same conditions that foster the acquisition of a second language. The teacher is responsible for providing the understandable language (comprehensible input), along with whatever supports are necessary in order for the students to understand the message. Using approaches and materials that add context to the language such as props, gestures, and pictures, all contribute to the students' acquisition and eventual verbal production of language" (p. 56).

The above statement suggests that, the language presented by the teacher, the environment in which the language is presented, and the strategies used in presentation are very important considerations for the instructor if the aim is to facilitate student comprehension and language skills. A comprehensive presentation by Richards and Rodgers (2001) revealed some of the strategies that have been applied in language instruction over the years. These include GrammarTranslation, Direct, Reading, Audio-Lingual, Cognitive, Counseling Learning, Comprehension-Based, and Communicative approaches.

The Grammar-Translation method involves having students translate sentences from their native language into the target language. Mostly, with this approach the emphasis is less on student ability to speak and more on grammar and translation. When faced with questions that require speaking, students are allowed use gestures and other nonverbal responses. The Direct approach on the other approaches does not allowed students the opportunity to apply their native tongue. Students are immediately immersed into studying the new language they plan to acquire.

Another approach that is used in language instruction is the Reading approach where the emphasis is placed on being able to read and build vocabulary in the secondary language. This approach requires more control over the frequency and usage of the vocabulary. Similarly, the Audio-Lingual method involves focusing attention on pronunciation and oral drillings.

The last four approaches have some similarity to the afore-mentioned methods but however have some unique characteristics. The Cognitive approach, for instance, involves emphasizes on rule acquisition and the instructor views reading and writing as important as students' ability in listening and speaking. That students are able to understand and comprehend the language are the main objectives put forth in the Counseling Learning, Comprehension-based and Communicative approaches. In these methods listening comprehension, language use, and fluency of use are viewed as important. These will lead into students' ability to read and write the language over time which allows speaking, reading, and writing over time. Finally the Communicative Approach emphasizes where language use and fluency of use is emphasized.

With all these approaches it is essential that the instructor provides a supportive environment, adequate communicative practice, and applicable learning activities to assist students. Another element of importance is the language learners' acquisition of vocabulary. According to Nation (2001) learning a second language involves learning vocabulary or words. Researchers have noted that extensive reading helps improve learners' vocabulary knowledge and 
skills (Mezynski, 1983, Krashen, 1989, Anderson, 1999, Fraser, 1999). In addition, the provision of meaningful input, communicative teaching methods, and authentic materials is essential to ensure the development of learners' vocabulary and communicative competence.

\section{B. Using Literary Texts in Language Instruction}

The review of teaching methods used in ESL classrooms showed that reading, listening, speaking, and writing are four important activities emphasized in language learning. Language textbooks provide the opportunity for practicing these essential components. However, using only textbooks in ESL instruction has been found to be insufficient.

For instance, from a three-month in-depth investigation of the use of ESL textbooks with Taiwanese students from 56 participating high schools, Chen, Chen, and Sun (2010) found that the books used offered few opportunities for students to expand their vocabulary beyond the first 2,000 words and academic words. Chen, Chen, and Sun went on further to suggest the use of novels as a good written supplementary source, as they involve extended reading. An assessment of the literacy skills among the Taiwanese students in Chen et al's study showed a significant improvement in reading scores among the participants when literary texts were included in instruction. The use of literature provides the opportunity for ESL students to interact with the language as they get to learn new words or vocabulary.

In another study by Horst, Cobb, and Meara (1998) in which 34 second language learners were included as study participants, the results revealed that students learned new words, built associations between them as a result of using reading literary materials. More importantly, through the use of the materials the students acquired vocabulary and knowledge of the words learned lasted over a period of at least 10 days.

In addition to helping students build vocabulary, other suggested benefits of using literature books are that they are motivating and authentic, provide a narrative and plot to stimulate interest, build up interest for other cultures, and help build fluency (Horst, 2005). Furthermore, literature books are often less expensive and may come with other supplementary material such as tapes, CD-ROMs, and movies that make comprehension easier.

The afore-mentioned studies have submitted that reading or using literature in ESL classrooms does encourage vocabulary learning. Although, the evidence suggests that these materials can ensure language proficiency levels at all levels of education, one drawback that has pointed out is that the texts do not present curricular items in a particular sequence as textbooks do (Gareis, Allard, \& Saindon, 2009). For instructors who emphasize sequencing, this might be an important issue worthy of consideration. One way to resolve this issue might be for such instructors to be very selective in the choice of the text used and considerate about when such texts need to be included in the curriculum. Also, since literary materials might present some cognitive difficulties for students, instructors might want to consider the inclusion of other presentations or supplementary materials to support learning.

Learning a "new" language could be difficult and the process may present challenges for most learners. It is therefore important that instructors in such classrooms find ways to encourage and support student learning. Since the use of technology has been deemed as one of the ways to positively support the teaching and learning process in general, it might be a good option for consideration in ESL classrooms.

\section{Using Multiple Technologies in Language Instruction}

The rapid development of technology and evidence presented regarding the effects of technology integration in instruction has made this approach popular in the teaching and learning process. Through the use of word processors, presentation software, multimedia, hypermedia, drill and practice programs, the Internet, and other procedures and tools, students from all walks of life are able to engage in instruction and the learning environment designed to meet their specific needs.

Language teaching is one area in which the application of technology has been encouraged. So far, technological equipment such as radio, TV, cassettes, CD-ROMs, DVDs, and communicative tools such as e-mails, chat rooms, discussion boards, and internet conferences are being used in language classes. According to Usun and Kömür (2009), technology such as movies and music can help instructors in language classes by providing them a good opportunity to develop and create different, enjoyable tasks for their classes. Wang (2004) also added that the use of technology helps meet language learners communication needs as well as help them develop their language skills in the classroom. Using various kinds of technological devices gives language students the sense of freedom, motivation, and encouragement they need for learning (Genc- Ilter, 2009).

Audio and visual technologies in the form of graphics, pictures, maps, and videos have been used in ESL instruction. Audio materials encourage listening skills while the visual presentation not only provide a focus of attention but also makes it easier for language learners to fill in any information they do not understand. The concern though is that some students may view the visual content passively and may garner very little meaning from the presentation. Presenting the visual information first and then and then following up with the audio is one strategy that has been suggested to prevent this problem.

It must be pointed out that using both audio and visual presentations simultaneously lead to a higher effect when compared to a single presentation at one time (Mayer, 2001).Together, these presentations attract the students' attention and help them understand the gist of the subject matter being presented. Audio-visual materials present students with a lot of information, especially in the form of cues such as facial expression, hand movement, and gestures which hold their attention and may encourage even the novice learner to focus on the message at hand. In addition, the 
representations enhance learners' listening comprehension and helps with understanding of difficult materials (Ginther, 2001). Video segments are known to be the best presentation since they spark interest by presenting information using multimedia formats and the language learners are able to link such presentations to enable comprehension.

Results from some empirical studies conducted on the subject support the points mentioned above. Pawling (1999) investigated 11 participants reaction to language learning using CD-ROM packages. The packages included multimedia presentations of video, text, photograph and sound. The findings showed that the use of the CD-ROM promoted collaborative learning while ensuring autonomous learning.

Similarly, Tsai and Jenks (2009) conducted a quasi-experimental study to explore the effect of using a $C D-R O M$ program as a supplement in teaching English language students. A total 87 students participated in the study. Two intact classes were assigned to the control and the experimental groups for four weeks. The students in the experimental group were assigned to two weekly one-hour sessions of use of a Teacher Guided Multimedia CD-ROM program while the control group received traditional instruction. The results from a vocabulary test showed that the experiment group achieved better English vocabulary acquisition compared to the control group.

Sarica and Cavus (2008) on the other hand studied e-learning among English language learners. The courses offered learning through chat rooms, net meetings with the entire class, and pen pal search engines. The findings showed that the e-learning approach helped enhance student learning. However, using 14 third-year university students as participants in a study where language was taught by way of the Internet, Kartal and Uzun (2010) observed that the students lacked physically, contextually and pedagogical skills at the end of the program.

In short, most of the research indicate that the use of technology in language classes helps improve the four skill areas recommended for success, that is, listening (Belz, 2002), speaking (Kung, 2003), writing (Anderson and Speck, 2001), and reading (Case \& Truscott, 1999, Deeler and Grey, 2000). Genc- Ilter (2009) strongly recommends the following for successful integration of technology in the language curriculum: instructors need to focus on the importance of using authentic and interactive activities, materials should be selected with the needs and interests of the students in mind, the lessons should meet pedagogical requirements, and the activities should be well supported by the technology.

\section{METHOD}

\section{A. Research Design and Participant Selection}

This study used a qualitative approach to describe how technology was used to successfully teach literature in an ESL class and explore students' reactions to the use of technology in the ESL classroom. An IRB was used to seek permission to conduct the study. Purposeful sampling was used in selecting participants for the study. Contact with the participants was initiated by way of recruitment letters handed out during a class visit. Students who indicated their willingness to take part in the study were asked to complete an informed consent form prior to participation.

The study participants comprised of 10 Thai students who were studying English as a second language, six females and four males. Five of the students were Language and Vocational Training third year (LVT) students and the other five were first-year in the International English Program (IEP). In addition to majoring in ESL, the IEP students were also majoring in International Business. Chinua Achebe's 1958 novel, Things Fall Apart, was used with a variety of audio-visual devices to teach literature to this group of ESL students. The technological devices included David Orere's 1987 movie on Things Fall Apart, a video interview by the British Broadcasting Corporation (BBC) Book Club (2006) with the book's author, Chinua Achebe, and a CD-ROM package consisting of listening exercises. In addition, computer technology, the Internet, and an overhead projector were used in the presentation of literary materials to the students.

\section{B. Data Collection and Analysis}

Data for the study were collected by way of one-on-one interviews. Two 45-minute semi-structured interviews were conducted with each participant during the semester of instruction. The first interview was conducted at the beginning of the semester to determine how much students knew about colonization and post colonial literature. During the interview, students' vocabulary skills were also evaluated. The second interview was conducted at the end of the semester to determine the extent of improvement in students' vocabulary as well as their knowledge on colonization experiences as a result of employing the literary materials and technology. Specifically, students' perception of the use of technology in the teaching of literature in the ESL classroom was assessed.

The interview data was transcribed, coded, and analyzed for themes as suggested by Patton (2002). In reporting the findings of the study, a lot of effort was made to ensure participant confidentiality. Pseudonyms were used in place of the participants' actual names. Also, to ensure accuracy, member checking was to make sure that the transcribed data reflected the actual responses of the students.

\section{FINDINGS}

The results of the study are reported in two phases. The first phase reports data from the first interviews while the second phase reports data from the interviews conducted at the end of the semester. 
The first phase of data collection helped the instructor of the class determine the teaching strategies that would help reach the needs of the students. Students' responses confirmed that they had no prior understanding of colonialism and postcolonial literature. One male student said: I think I can [define] colonialism...but I do not know of any colonial literature. Another said: That's a big word [colonialism] ...I do not understand literature [written in English] ...I need [to] the English first.

Regarding vocabulary, the LVT students had a medium proficiency level. Almost all of them could construct basic grammatically correct sentences in English using the appropriate vocabulary and that could be explained by the fact that they had previously taken 2 years of consistent English classes, and before that, many of them had taken ESL classes in primary school. The IEP students had a higher level in vocabulary, due to a higher volume of English course hours they had taken. In each of these classes, the researcher focused (among other tasks and assignments) on improving the vocabulary proficiency of the learners. To that effect, he used the vocabulary instructions provided by the course manual, plus other activities that he created. After reading each text, the students were asked to read the new words in the text, plus their definitions. After that, the instructor would ask volunteer students to construct an English sentence containing the new word they had learned in the reading of the day.

The second set of interviews revealed changes in student understanding of the novel in general, the terminology in the novel, specifically, as well as their use of the vocabulary. Also students indicated that they found the use of technology in the teaching of literature in this course effective.

\section{Influences of Multiple Technologies}

The students perceived the technological devices as education tools that helped enhance their understanding and engagement with the colonization and postcolonial experience portrayed in the book. The general reactions from the students show that the technology enabled easier and accurate evaluation of the characters and events in the literature. One of the LVT male students stated:

The use of videos and CDs made it easier for me to understand the issue of colonization in Things Fall Apart. I was able to understand and analyze Okonkwo's behavior with a lot of details in my assignments. Seeing how Okonkwo walks on the TV screen enabled me to realize how aggressive this character is.

The students realized that weaving technology within the Literature curriculum equips them with high listening and comprehension skills that in turn facilitate their discussion of the literary text. One of the LVT female students said:

The use of listening and comprehension CDs in this class prepared me to understand Things Fall Apart when we studied it. I was able to understand everything people said in the video because our instructor had initially had several listening and comprehension assignments and sessions with us.

Using technology in this class produced a familiarity between students and the setting of the novel Another LVT female student stated that:

The use of the internet enabled me to locate geographically where Africa (Nigeria precisely) and Britain are. I was therefore able to link the areas in Things Fall Apart with the mental map that I acquired after seeing Nigeria and Britain on the screen when our instructor pulled the map of the world from the internet and projected it.

The participants also indicated that the use of technology in this class enabled them to have more interaction and feel more proximity with the literary material; it saved the participants enormous efforts that would have been invested in trying to imagine or picture the characters as they are portrayed in a written text. It appeared the technology made it easier for students to draw comparisons between the plot in the book, the setting and conflicts in the text, and their personal environment and society. One female student in the LVT section said:

Seeing Okonkwo in the video enabled me to judge him better as a character: his bushy hair made me think that he resembles a spirit, a being that is super human and can even be scary. Being able to see Okonkwo made me think that he is a good man: he did not speak much, he was "a man of action" as good men are in Thailand.

One female IEP student also voiced a similar opinion:

The use of the movie and the internet made me understand the book so well that I can have a strong opinion after watching it: the colonizer was trying to change the "nationality" of the Africans, and nationality is called sanchaat in Thai language. Watching the movie on Things Fall Apart and listening to Achebe's interview and listening to our instructor as he showed us the map of the world helped me acquire many new English words and expressions like "colonization, brutality, intrusion, usurpation, subaltern, oppression" and several other words that I had never heard or understood before.

The data showed that the use of technology in this class empowered the students to such an extent that remarkable and striking inferences were made in their study and discussion of the text, and the learners felt that they improved their skills in Literary criticism and beyond that, their overall level in English language improved. One female LVT student said:

Watching the video enabled me to conclude that the missionaries came to Nigeria in search of better living conditions just like the Thai people migrated from China searching for better living conditions. Had I limited myself to reading the book, $i$ would not have been able to arrive at such a conclusion. Watching the movie empowered me as a critic. It gave me an understanding and a confidence that I would not have had from the reading of the book only. The fact that we watched the movie and discussed it and listened to CDs helped me to overcome my limits in the English class. 
Another feature that emerged from the study is the tendency to substitute the movie for the literary text, instead of combining the use of the printed text with the movie. One male IEP student voiced that:

I tried to read Things Fall Apart but I could barely understand it. The words were so difficult for me that I had to pick my English Thai dictionary almost ten times on each page. When we started to watch the movie, I stopped reading the book and by the time we finished the movie, I had a total understanding of the book.

She goes further to reiterate the numerous and amazing inferences that the movie enabled her to produce in her assignment on Things Fall Apart:

The yam festival in Things Fall Apart made me think about Lamjai festival, which is a seasonal festival in Thailand when we enjoy lamjai, a delicious fruit that I thought is as important to the Ibo people as lamjai is to us, Thai people. I can also compare the jam festival in Things Fall Apart to the OTP phenomenon which means "One Tombon, One Product", in other words a call for economic self sufficiency.

One female IEP student pushed the power of technology in terms of comparing societal features to the highest level. Her opinion is the most complex one, and it speaks for itself. She said: Okonkwo died-committed suicide-to empower his people, just like the Thai Seub Nakasatearn who shot himself because his boss would not listen to him in his great effort to protect wildlife in Thailand.

The student later pointed out that after Seub's death, considerable changes occurred in the protection of wild animals in Thailand. She went on further to say:

Okonwko also reminds me of the Thai Srithanonchai who was killed many years ago by the ruling authorities (around 100 or 200 years ago) because he was extremely smart. The issue of race is also a key aspect herein the picture; Okonkwo is a "black guy" who killed the head messenger in a white man's court, and the white man's behavior is "racism".

Another important feature that technology brought into this study is the specific details that contribute to add an interesting twist to the plot. Watching the movie enabled the students to grasp certain feelings and emotions that are difficult to capture in a simple reading of the text, especially for ESL students. One of the male IEP students stated this as portrayed in the following lines and she ends her comment with the ease with which she could draw a comparison between her society with pre-colonial Nigeria:

Looking at the arrival of the British colonizers in Nigeria made me realize how aggressive the British were, and I would not be able to notice the accuracy of that phenomenon if I had just read the book. In fact, the perseverance of the British colonizers made me think about the religious conflict that is currently going on in southern Thailand. I see the Thai Buddhists as the British colonizers in Things Fall Apart: They are trying to impose their religion (Buddhism) on Muslim southern Thai people.

The female IEP student who had previously compared Okonkwo to the Thai hero Srithanonchai also unveils the minute details that technology allowed the students to perceive in their study of the literary material:

The colonial experience is fully exposed in the movie, to such an extent that one can make a judgment on that experience, and I can say that the colonial experience was good: the white master did well by building a court of justice and other facilities, and Okonwko and his friends in Things Fall Apart deserved to be imprisoned because justice had to be done.

\section{DISCUSSION}

The data gathered in this study supports Kay's (1982) argument that "Literature does indeed have a place in ESL curriculum. For many students, literature can provide a key to motivating them to read in English. For all students, literature is an ideal vehicle for illustrating language use and for introducing cultural assumptions" (p. 536).

In addition, using literature in combination with the multiple technologies in the ESL classroom made it easier for the ESL students to understand the material which was initially construed as difficult to grasp. The study also shows that using audio-visual materials in the form of movies on a book prepares students to a more complete and complex reaction to the material and it also generates critical thinking as NCLE (2002) stipulates. The use of listening materials also prepares students and equips them with a better ability and predisposition to understanding and analyzing literary materials as some of the students pointed out in this research. The universal nature of the human experience is expressed best by the use of audio visual materials in the Literature classroom. The spoken word in movies transports students beyond their personal, individual and restricted world to a global world where human experiences mingle and overlap, as the colonial and the non colonial experience intersected in this research. The current study confirms what several researchers (Koskinen,Wilson, \& Jansema,1985; Neuman \& Koskinen,1992) demonstrated in their advocacy of the use of television and closed-captioning in the ESL classroom, but this research also goes beyond what they said. This research reveals that the use of literary materials with audio-visual technologies such as listening CD-ROMs, movies or videos based on the literary materials, and the computer technology and the internet may help ESL students more than the use of single technologies such as televisions with closed-captioning. This project showed that carefully selecting an audio visual material and introducing students to it while placing specific emphasis on vocabulary and prior knowledge factors as Koskinen et al.,(1985) reiterate, facilitates the teaching of Literature in the ESL classroom.

\section{RECOMMENDATIONS}


Based on the results of this study, it is recommended that technology and other literary materials be used in the ESL classroom. Videos and movies based on books encompass several benefits that cannot be achieved when and instructors limit themselves to the print culture. Both ESL and Literature faculty need expose students to the use of audiovisual technology. ESL student exposure to literature is also recommended. Such an approach is somehow similar to the concept of English Studies that currently exists in the English department in certain colleges, a strategy that encourages students to combine Literature, Writing (Composition), Language and Pedagogy in their study of texts. Using technology and Literature in the ESL classroom helps train "strong readers" as Robert Scholes states in The Rise and Fall of English: readers who competently and confidently engage literary materials while bringing their own personal experience into that of the characters in the text. Several questions and issues face the practice advocated in this research and they can be considered as the basis for subsequent research. Questions given the issue of limited funding these days, how can ESL programs efficiently and successfully match technology applications to the instructional needs and goals of ESL programs? This is a challenge that instructors and educational administrators face, making this an area worthy of investigation. Finally, the digital divide remains a huge obstacle to overcome. The rift between those who have access to technology and those who do not is giant and must be considered.

\section{REFERENCES}

[1] Achebe, C. (1958). Things Fall Apart. London: Heinemann.

[2] Anderson, R \& B. Speck. (2001). Using technology in K-8 literacy classrooms. Upper Saddle River, N: J: Prentice Hall.

[3] BBC World Service. (2006). Interview with Chinua Achebe.

[4] Belz, J. (2002). Social dimensions of telecollaborative foreign language study. Language Learning and Technology, 6(1), 60-81.

[5] Brindley, G. (1998). Assessing listening abilities. Annual Review of Applied Linguistics, 18, 171-191

[6] Case, C., \& Truscott, D.M. (1999). The lure of bells and whistles: Choosing the best software to support reading instruction. Reading \& Writing Quarterly, 15, 361-369.

[7] Educational Resources Information Center. (2002). Uses of technology in adult ESL education. Online Submission.

[8] Ehrmann, S. C. (2002). Improving the Outcomes of Education: Learning from Past Mistakes. Educause Review, 37(1). Online Submission. http://net.educause.edu/ir/library/pdf/ERM0208.pdf

[9] Fraser, C. A. (1999). Lexical Processing Strategy Use and Vocabulary Learning through Reading. Studies in Second Language Acquisition, 21(2), 225-241.

[10] Gareis, E. (1997). Literature and film adaptations: Dealing with hot topics in the ESL and literacy classroom. Journal of Adolescent \& Adult Literacy, 41(3), 220-222.

[11] Gareis, E., Allard, M., \& Saindon, J. (2009). The novel as textbook. TESL Canada Journal, 26(2), 136-147.

[12] Genc Ilter, B. (2009). Effect of Technology on Motivation in EFL Classrooms. Online Submission.

[13] Ginther A. (2002). Context and content visuals and performance on listening comprehension stimuli. Language Testing, 19(2), 133-167.

[14] Hicks, M., Reid, I.,\& George, R. (2001). Enhancing online teaching: Designing responsive learning environments. The International Journal for Academic Development, 6 (2),143-151.

[15] Hourigan, T., \& Murray, L. (2010). Using blogs to help Language Students to develop reflective learning strategies: Towards a pedagogical framework. Australasian Journal of Educational Technology, 26(2), 209-225.

[16] Jelfs, A., and Whitelock, D. (2000).The notion of presence in virtual learning environments: What makes the environment 'real'? British Journal of Educational Technology, 31(2) 145-152.

[17] Kartal, E., \& Uzun, L. (2010). The internet, language learning, and International Dialogue: Constructing online foreign language learning websites. Turkish Online Journal of Distance Education, 11(2), 90-107.

[18] Krashen, S. (1989). We acquire vocabulary and spelling by reading: Additional evidence for the input hypothesis. Modern Language Journal, 73(4), 440-464.

[19] Kay, S. (1982). Literature in the ESL classroom. TESOL Quarterly, 16 (4), 529-536.

[20] Koskinen. P., Wilson, R., \& Jensema, C. (1985). Closed-captioned television. A new tool for reading instruction. Reading World, 24,1-7.

[21] Li, C. H. (2006). What you know and see can help you: An examination of the effects of advance organizers, visual images, and gender differences on the video-based listening comprehension of EFL college students. Dissertation Abstracts. Indiana University of Pennsylvania. AAT 3240172

[22] Liu, Y. (2007). Designing quality online education to promote cross-cultural understanding. In A. Edmundson (Ed.), E-learning. cultural challenges (pp.239-254). Hershey, PA: Information Science Publishing.

[23] Lund, R.J. (1990). A taxonomy for teaching second language listening. Foreign Language Annals, 23, 105-115.

[24] Mansoor I. (2002). The REEP program perspective: The benefits \& challenges of technology. Uses of Technology in Adult ESL Education.

[25] Matsuoka, W., \& Hirsch, D. (2010). Vocabulary learning through reading: Does an ELT course book provide good opportunities? Reading in a Foreign Language (2010), 229, 56-70.

[26] Mayer, R. E. (2001). Multimedia Learning. Cambridge: Cambridge Press.

[27] Mayer, R. E., Moreno, R., Boire M., \& Vagge S. (1999). Maximizing constructivist learning from multimedia communications by minimizing cognitive load. Journal of Educational Psychology, 91, 638-643.

[28] Merriam, S.B., \& Caffarella, R.S. (1999). Learning in adulthood ( $2^{\text {nd }}$ ed.).San Francisco: Jossey-Bass.

[29] Mezynski, K. (1983). Issues concerning the acquisition of knowledge: effects of vocabulary training on reading comprehension. Review of educational research 2, 253-279.

[30] Nation, I. S. P. (2001). Learning vocabulary in another language. Cambridge: Cambridge University Press. 
[31] Neuman, S. B., \& Koskinen, P. (1992). Captioned television as comprehensible input: Effects of incidental word learning from context for language minority students. Reading Research Quarterly, 27 (1), 94-106.

[32] Orere, D. (1987). Dir. Things Fall Apart.

[33] Patton, M. Q. (2002). Qualitative evaluation and research methods (3rd ed.). Thousand Oaks, CA: Sage Publications, Inc.

[34] Pawling, E. (1999). Modern languages and CD-ROM-based learning. British Journal of Educational Technology, 30(2), 163-75.

[35] Pellicer-Sanchez, A., \& Schmitt, N. (2010). Incidental vocabulary acquisition from an authentic novel: Do Things Fall Apart? Reading in a Foreign Language, 22(1), 31-55.

[36] Richards, Jack C. Rodgers, Theodore S. (2001). Approaches and methods in language teaching. Cambridge; Cambridge University Press.

[37] Sarica, G., \& Cavus, N. (2008). Web-Based English Language Learning. Online Submission.

[38] Scholes, R. (1998). The rise and fall of English. Yale: Yale University Press.

[39] Smith, D. R., \& Ayers, D. F. (2006). Culturally responsive pedagogy and online learning: Implications for the globalized community college. Community College Journal of Research and Practice, 30, 401-415.

[40] Thompson, L., \& Ku, H. (2005). Chinese graduate students' experiences and attitudes toward online learning. Educational media international, 42 (1), 33-47.

[41] Thorne, S., Black, R., \& Sykes, J. (2009). Second Language Use, Socialization, and Learning in Internet Interest Communities and Online Gaming. Modern Language Journal, 93(1), 802-821.

[42] Tsai, R., \& Jenks, M. (2009). Teacher-guided interactive multimedia for teaching English in an EFL context. Journal of Educational Multimedia and Hypermedia, 18(1), 91-111.

[43] Usun, S and Kömür,S. (2009). Marketing of distance learning in ELT programs: The challenges for marketing distance education in online environment. Online Submission.

[44] Wang, Y. (2004). English magazines, motivation, and improved EFL writing skill. English Teaching Forum, 42(1), 24-29.

Moussa Traore is an Assistant Professor in the English Department at North Shore Community College in Danvers, Massachusetts. His expertise and training is in Comparative Literature, Composition and ESL. His assignment at North Shore Community College includes teaching Composition, African and American Literature and Global Literature. Dr Traore's research agenda focuses on the use of postcolonial texts in ESL and the literary manifestations of the relations between continental Africans and the diaspora.

Lydia Kyei-Blankson is an Assistant Professor in the Educational Administration and Foundations Department at Illinois State University. Her expertise and training is in research methods, applied statistics, and psychometrics. Her assignment at ISU includes teaching research methods and statistics graduate courses in the College of Education. Dr. Kyei-Blankson's research agenda focuses on the scholarship of teaching and learning and the implications of effective technology integration in teaching and learning. 